\title{
Three interesting cases of syndrome of inappropriate antidiuretic hormone secretion
}

\author{
Monika Dyczko', Małgorzata Sawa' , Anna Grzywa-Celińska², Katarzyna Szmygin-Milanowska², \\ Maryla Kuczyńska³, Jerzy Mosiewicz ${ }^{1}$ \\ ${ }^{1}$ Chair and Department of Internal Diseases, Medical University of Lublin, Poland \\ ${ }^{2}$ Chair and Department of Pneumonology, Oncology and Allergology, Medical University of Lublin, Poland \\ ${ }^{3}$ The Scientific Society of Students at the Department of Internal Diseases, Medical University of Lublin, Poland
}

Dyczko M, Sawa M, Grzywa-Celińska A, Szmygin-Milanowska K, Kuczyńska M, Mosiewicz J. Three interesting cases of syndrome of inappropriate antidiuretic hormone secretion. J Pre-Clin Clin Res. 2015; 9(2): 174-176. doi: 10.5604/18982395.1186502

\begin{abstract}
The syndrome of inappropriate antidiuretic hormone secretion (SIADH) is an etiologically-diverse pathological condition resulting from the elevation in both ectopic and autonomic secretion of the antidiuretic hormone (ADH) by neoplastic tissue; excessive stimulation of the hypothalamic-pituitary axis, e.g. in pulmonary diseases, central nervous system (CNS) abnormalities, endocrine glands dysfunction or due to the use of some medications; intensification of renal ADH action by certain medications and action of substances chemically-related to vasopressin. The clinical characteristics of the syndrome are comprised of the presence of inadequately concentrated urine, hyponatremia, and hypo-osmolal blood serum, as well as weight gain. To show the variety of its causes and courses the article presents three cases of patients diagnosed with SIADH in the Department of Internal Medicine. In each of them the syndrome of inappropriate antidiuretic hormone secretion manifested in clinical laboratory tests in the form of hyponatremia.
\end{abstract}

\section{Key words}

syndrome of inappropriate antidiuretic hormone secretion, hyponatremia, diagnostics

\section{INTRODUCTION}

The name 'syndrome of inappropriate antidiuretic hormone secretion' (SIADH) is reserved for etiologically-diverse pathological conditions resulting from the elevation in both ectopic and autonomic secretion of the antidiuretic hormone $(\mathrm{ADH})$ by neoplastic tissue $[1,2,3]$; excessive stimulation of the hypothalamic-pituitary axis or due to use of some medications $[4,5,6]$; intensification of renal ADH action by certain medications and action of the substances chemicallyrelated to vasopressin. The clinical characteristics of the syndrome are comprised of the presence of inadequately concentrated urine, hyponatremia, and hypo-osmolal blood serum, as well as weight gain. Yet, surprisingly, in this syndrome neither peripheral edema nor ascites are present [7]. To show the variety of its causes and courses three interesting cases of SIADH are presented

\section{CASE I}

SIADH as a result of central nervous system ischemia. A 54-year-old female patient with no history of chronic diseases was admitted to the Department of Internal Medicine due to hyponatremia stated in the ambulatory test. The patient had been undergoing complex neurological diagnostics for the previous month in order to determine the underlying cause of her collapse; which was further accompanied by the occipital headaches as well as balance disorders. A head CT scan was performed during the patient's stay at the Department of

Address for correspondence: Anna Grzywa-Celinska, Chair and Department of Pneumonology, Oncology and Allergology, Medical University, Lublin, Staszica 16 20-081 Lublin, Poland

E-mail: acelin@op.pl

Received: 31 July 2013; accepted: 04 September 2015
Neurology and revealed two hypodense lesions, indicating ischemic damage of the brain. The patient did not report any symptoms at the time of admission to the Department of Internal Medicine. The physical examination was unremarkable. Further laboratory data indicated an advanced hyponatremia with sodium levels of 121-122 $\mathrm{mmol} / \mathrm{l}$. The blood morphology results, urinalysis, as well as potassium, creatinine, glucose, transaminases, TSH, adrenocorticotropic hormone and fasting cortisol concentrations were within normal ranges. Arterial blood analysis indicated low serum osmolality measured as $249 \mathrm{mOsm} / \mathrm{kg} \mathrm{H} 2 \mathrm{O}$ (norm: 270$300 \mathrm{mOsm} / \mathrm{kg} \mathrm{H}_{2} \mathrm{O}$ ), whereas the urinary sodium excretion was unaltered, at the level of $122 \mathrm{mmol} / 24 \mathrm{~h}$ (norm: $40-$ $220 \mathrm{mmol} / 24 \mathrm{~h}$ - this is a standard specified by the central laboratory where the sample was analyzed).

Ultrasound examination of the abdominal cavity and chest X-ray revealed no significant anomalies. In addition to the proper kidney, thyroid and adrenal gland function, along with low plasma osmolality, the diagnosis of the SIADH was made. An abdominal CT was performed as a part of diagnostic measures taken to discover the underlying cause of the SIADH syndrome, and was found to be unremarkable. The treatment regimen included restriction in daily fluid supply to $1.5 \mathrm{l}$, as well as additional sodium chloride supplementation. This allowed for an increase in the plasma sodium concentration $(137 \mathrm{mmol} / \mathrm{l})$, together with normalization of the serum osmolality.

\section{CASE 2}

SIADH syndrome associated with neoplastic process. A 73-year-old male patient presented to the Psychiatry Clinic with complaints of progressive deterioration of his psychological condition, loss of appetite, sleep disturbances, 
anhedonia, and suicidal thoughts for the past three months. His past medical history included controlled chronic hypertension, hyperthyroidism, paroxysmal atrial fibrillation and transurethral prostatic resection due to prostatic hyperplasia. As the patient was under observation in the clinic, his mental condition improved systematically, with the suicidal thoughts subsiding and a significant improvement in mood. Routine laboratory tests demonstrated an advanced hyponatremia, sodium concentrations measured from two samples amounted to 118 and $120 \mathrm{mmol} / \mathrm{l}$, respectively. The patient was transferred to the Internal Medicine Department in order to conduct further diagnostics. After admission, the patient exhibited recurrent episodes of vomiting, general malaise, loss of appetite and considerable weight loss (approximately $10 \mathrm{~kg}$ within 2 months). The physical examination was unremarkable, except for the patient being cachectic (BMI $18.4 \mathrm{~kg} / \mathrm{m}^{2}$ ). Further laboratory testing showed remaining hyponatremia with sodium level of $128 \mathrm{mmol} / \mathrm{l}$. No significant pathologies were observed with reference to both blood morphology, as well as remaining electrolyte, urea, creatinine, glucose, TSH and cortisol concentrations. A plasma hypo-osmolality $\left(250 \mathrm{mOsm} / \mathrm{kg} \mathrm{H}_{2} \mathrm{O}\right)$ was revealed through blood gasometry testing; nonetheless, the sodium excretion measured in routine 24-hour urine collection remained normal - $153 \mathrm{mmol} / 24 \mathrm{~h}$. In order to determine the underlying cause of the SIADH and because of patient's weight loss along with nausea and vomiting, a chest X-ray was performed in which radiolucent, emphysematous spaces were depicted over the lung fields. The abdominal ultrasound examination demonstrated an image suggesting multiple metastatic lesions throughout the liver. The neoplastic characteristics of the lesions was confirmed with MRI of the abdomen. Furthermore, the MRI revealed extra neoplastic foci located in lumbar spine vertebrae, the sacrum, pelvis and ribs. Considering the patient's mental disturbances and nausea, as well as recurring emetic episodes, a head CT scan was performed, revealing several hypodense areas located in the cerebral hemispheres, most probably of metastatic characteristics. In order to localize the primary neoplastic focus, a chest CT was performed and the patient scheduled for both gastro- and colonoscopy.

A pathological infiltration of not only the right lung hilum, but also the right main bronchus and superior vena cava, along with numerous enlarged mediastinal lymph nodes were depicted. The diagnostic material for histopathological examination was obtained from the mediastinal lymph node during endobronchial ultrasound procedure. The results of the histopathological investigation confirmed the diagnosis of a small cell carcinoma of the lung.

\section{CASE 3}

SIADH - cause unknown. A 79-year-old female patient treated for chronic hypertension was admitted to the Department of Internal Medicine due to consecutive episode of bilious vomiting and hyponatremia of $111 \mathrm{mmol} / \mathrm{l}$. During past 2 years, the patient was hospitalized in the Internal Medicine Ward for three times. Each hospitalization carried the same complaints of persistent vomiting accompanied by severe electrolyte disturbances in form of hyponatremia (laboratory data of plasma sodium content on admission were 114, 114 and $117 \mathrm{mmol} / \mathrm{l}$, respectively). All the diagnostic imaging procedures (chest X-ray, abdominal ultrasound examination), as well as basic laboratory testing (blood morphology, serum $\mathrm{K}+$ concentration, transaminases, fasting glucose, TSH, fasting cortisol concentrations, double designation circadian rhythm of cortisol secretion) performed during consecutive hospitalizations did not exhibit any considerable deviations from the normal ranges. A head CT scan performed due to the patient's serious condition and alteration in consciousness during one of the admissions, excluded the existence of any notable pathologies. The arterial blood acid alkaline balance revealed low osmolality of the blood plasma- $250 \mathrm{mOsm} / \mathrm{kg} \mathrm{H} 2 \mathrm{O}$; however, the urinary sodium excretion level was indicated as $69 \mathrm{mmol} / 24 \mathrm{~h}$. On the basis of the above-mentioned, exclusion of kidney failure, as well as both adrenal and thyroid insufficiency (for which the patient was examined during previous hospitalizations), the SIADH was diagnosed. Unfortunately, the patient refused further diagnostic procedures concerning investigation of the possible cause of her ailment. The treatment regimen consisted of fluid supply restriction to a maximum of 11/ day, with additional sodium chloride compensation. These proceedings led to stabilization of the plasma sodium concentrations within normal limits.

In each of the three presented cases of patients diagnosed of SIADH in the Department of Internal Medicine, the syndrome of inappropriate antidiuretic hormone secretion manifested in clinical laboratory tests in the form of hyponatremia - one of the most common abnormalities of electrolyte balance $[1,4,8]$. The frequency of its occurrence was calculated as $1 \%$ in the total population and over $15 \%$ of in-patients [9]. Low serum level of natrium can be a sign of numerous medical conditions including SIADH. Pahdi et al. [6] conducted a big $(n=730)$, prospective study to assess the frequency, risk factors, and outcome in Intensive Care Unit patients with critical conditions and hyponatraemia. On admission, hyponatraemia was diagnosed in $34,3 \%$ patients, the main cause of which was SIADH as a consequence of pneumonia. Other predisposing factors included: severe sepsis, trauma, surgery, drugs, renal failure, heart failure, liver cirrhosis, subarachnoid haemorrhage, hypothyroidism and hypocortisolism.

However, hyponatremia accompanied by normovolemia tends to form a typical constellation, most often indicating the SIADH syndrome. Except for these two abnormalities, SIADH is always associated with: extracellular fluid hypoosmolality at levels below $275 \mathrm{mOsm} / \mathrm{kg} \mathrm{H}_{2} \mathrm{O}$, inadequate urine concentration, commonly exceeding the osmolality level of $100 \mathrm{mOsm} / \mathrm{kg} \mathrm{H}_{2} \mathrm{O}$, lack of edema or dehydration signs (isovolemia), urinary sodium excretion $>40 \mathrm{mmol} / 24 \mathrm{~h}$ (despite regular sodium and water supply). The latter parameter stayed within recommended normal values, in spite of serum hyponatraemia, although the drop in urine natium excretion would be expected in this clinical situation. In every single case, the exclusion of other conditions leading to normovolemic hypo-osmolarity is mandatory.

The mechanism of these disorders is complex and depends on the triggering cause of the SIADH syndrome. The common element is abnormally high secretion of vasopressin, despite the absence of states stimulating the secretion such as increase of plasma osmolity or decrease in effective intravascular fluid volume. The high concentration of anti-diuretic hormone by stimulating receptors $\mathrm{V}^{2}$ in the kidney leads to the water retention, increase in urinary sodium excretion and 
hyponatraemia. In $14 \%$ of SIADH there occurs very low concentrations of vasopressin. This phenomenon may be caused by mutations in the genes for receptor proteins in the kidney that causes tubular hypersensitivity of antidiuretic hormone secretion or vasopressin acting like oxytocin e.g. [9].

The professional literature includes numerous descriptions of lung cancer-related SIADH syndrome in which the syndrome's metabolic, endocrine or mental disorders symptoms, as in presented Case 2, camouflaged or even delayed the diagnosis and proper treatment of the underlying lung carcinoma.

In spite of all the SIADH causes mentioned throughout the presented case studies, the conditions such as neoplasms located in systems other than respiratory - for instance, digestive tract tumours (pancreas, stomach, duodenum), nasopharyngeal tumours or lymphomas - can also be listed as possible initiators of inadequate vasopressin secretion. Furthermore, the CNS pathologies such as: stroke, meningitis, brain tumours, trauma, haemorrhage, GuillainBarre syndrome or neurosurgical interventions, may also be responsible for the appearance of the Schwartz-Bartter syndrome, as observed in Case $1[10,11,12,13,14]$.

For numerous reasons the underlying condition of SIADH often remains unknown. In the presented Case 3, the definite cause was the lack of patient's consent for the proposed diagnostic procedures. It has been proved that hyponatraemia is the independent risk factor for increased mortality [6, $15,16]$; therfore, no significant observation may be drawn also from the author's clinical experiences - every case of hyponatremia manifested in random laboratory tests should be given an in-depth clinical differentiation including the $\mathrm{SIADH}$, as it may advance revealing the proper underlying disease and making a life-saving diagnosis.

\section{REFERENCES}

1.Platania M, Verzoni E, Viali M. Hyponatremia in cancer patients. Tumori. 2015; 28: 101(2): 246-8.

2. Grohe C, Berardi R, Burst V. Hyponatraemia - SIADH in lung cancer diagnostic and treatment algorithms. Crit Rev Oncol Hematol. 2015; (Epub ahead to print).

3. Karczmarek-Borowska B, Zielińska K, Bukała A. Hyponatremia in the course of small cell lung cancer-a case repor. Pol Merk Lek. 2014; 37(217): 49-52.

4. Amoako AO, Brown C, Ruley T. Syndrome of inappropriate antidiuretic hormone secretion: a story of duloxetine - induced hyponatraemia, BMJ Case Rep. 2015: 24.

5.Lange-Asschenfeldt C, Kojda G, Cordes J, Hellen F, Gillmann A, Grohmann R, et al. Epidemiology, symptoms, and treatment characteristics of hyponatremic psychiatric inpatients. J Clin Psychopharmacol. 2013; 33(6): 799-805.

6. Padhi R, Panda BN, Jagati S, Patra SC. Hyponatremia in critically ill patients. Indian J Crit Care Med. 2014; 18(2): 83-87.

7.Zgliczyński S. Nadmierne wydzielanie hormonu antydiuretycznego zespół Schwartz-Barttera. PAMW 1971; 47: 555-561 (in Polish).

8. Olsson K, Öhlin B, Melander O. Epidemiology and characteristics of hyponatremia in the emergency department. Eur J Intern Med. 2013; 24(2): 110-116.

9. Krysiak R, Okopień B. Zespół nieadekwatnego wydzielania wazopresyny, Przegl Lek. 2014; 71(5): 277-285 (in Polish).

10. Witek P. Postępy w rozpoznawaniu i leczeniu hiponatremii. Postepy Nauk Med. 2008; 2: 75-82 (in Polish).

11. Hoorn EJ, van der Lubbe N, Zietse R. SIADH and hyponatraemia: why does it matter? NDT Plus. 2009; 2 [Suppl 3]: iii5-iii11.

12. Hannon MJ, Thompson CJ. The syndrome of inappropriate antidiuretic hormone: prevalence, causes and consequences. Eur J Endocrinol. 2010; 162: 5-12.

13. Zhang YZ, Qie JY, Zhang QH. Incidence and mortality prognosis of dysnatremias in neurologic critically ill patients. Eur Neurol. 2015; 73(1-2): 29-36.

14. Saleem S, Yousuf I, Gul A, Gupta S, Verma S. Hyponatremia in stroke. Ann Indian Acad Neurol. 2014; 17(1): 55-7.

15. Funk GC, Lindner G, Druml W, Metnitz B, Schwarz C, Bauer P, Metnitz PG. Incidence and prognosis of dysnatremias present on ICU admission. Intensive Care Med. 2010; 36(2): 304-11.

16. Basu A, Ryder RE. The syndrome of inappropriate antidiuresis is associated with excess long-term mortality: a retrospective cohort analyses. J Clin Pathol. 2014; 67(9): 802-6. 